\title{
Representación gráfica de la cultura andina
}

\section{(c) (1) (2)(2)}

\section{Graphic representation of the Andean culture}

Rosa Belén Ramos Jiménez. ${ }^{1}$, Ana Lucía Rivera Abarca. ${ }^{2}$, Héctor Oswaldo Aguilar Cajas. ${ }^{3}$, Heidy Elizabeth Vergara Zurita. ${ }^{4}$

Recibido: 20-03-2019 / Revisado: 22-04-2019 /Aceptado: 14-05-2019/ Publicado: 05-06-2019

\begin{abstract}
DOI: https://doi.org/10.33262/cienciadigital.v3i2.6.519

The following study aims to represent a graphical Andean culture beyond the aesthetic view, using the main visual signs implicit in the inherited graphic of the pre-Columbian societies as a resource, especially the Andean one in order to achieve its approximation in the current graph.

Under this concept, an analysis of the Andean thought was made to understand the symbolism and therefore its relation with the social context. The composition, where the use of the Andean proportional system, compositional structures and schematic elements are verified, the same ones that will be used as resources in the creation of the new representations. Finally, aesthetics, where the conception of the form is revealed, which will be used as a graphic-plastic element that determines the construction of the graphic. It was possible to represent, through illustrations, various signs of the Andean culture by integrating all these elements, the achievement a mimicry between the present and the past. It is estimated that the results of the graphic analysis of the pieces created for this research can be a useful source for designers, illustrators and graphic artists, including the possibility of serving as a base for further graphic proposals that will elicit this research.
\end{abstract}

Keywords: Andino, Composition, Culture, Design, Esthetic, Lenguage.

\section{Resumen}

El presente estudio pretende representar gráficamente la cultura andina más allá de lo estético, usando como recursos los principales signos visuales implícitos en la gráfica heredada de las sociedades precolombinas, especialmente de la andina para lograr su aproximación en la gráfica actual. Bajo este concepto, se realizó un análisis del pensamiento andino para entender el simbolismo y por lo tanto su relación con el contexto social. La composición, donde se comprueba el uso del sistema proporcional

\footnotetext{
${ }^{1}$ Universidad, Facultad, Chimborazo, Ecuador, Email

${ }^{2}$ Universidad, Facultad, Chimborazo, Ecuador, Email

${ }^{3}$ Universidad, Facultad, Chimborazo, Ecuador, Email

${ }^{4}$ Universidad, Facultad, Chimborazo, Ecuador, Email
} 
andino, estructuras compositivas y elementos esquemáticos, los mismos que serán usados como recursos en la creación de las nuevas representaciones. Finalmente, la estética, en donde se revela la concepción de la forma, que se usará como elemento gráfico- plástico determinante en la construcción de la gráfica. Al integrar estos elementos se logró representar través de ilustraciones varios signos de la cultura andina, logrando un mimetismo entre el presente y el pasado. Se estima que los resultados del análisis gráfico de las piezas creadas para esta investigación, pueden constituir fuente útil para diseñadores, ilustradores y artistas gráficos, incluyendo la posibilidad de servir como base de futuras propuestas gráficas que amplíen esta investigación.

Palabras clave: andino, composición, cultura, diseño, estética, lenguaje.

\section{Introducción}

En el campo del diseño se toma como fuente de inspiración para nuevas creaciones los aportes ya generados con anterioridad, y en muchas ocasiones de aquellos signos y símbolos de culturas pasadas, pues su presencia, sobre todo en piezas arqueológicas, forman parte del bagaje cultural actual que está a la mano de diseñadores. Sin embargo, al repetirse una y otra vez sin lógica más que el acompañar a una composición gráfica, puede resultar en una asociación con el pasado sí, pero muy distante del entendimiento sobre la representación para las que fueron elaboradas.

El objetivo de este ensayo es realizar la representación gráfica de la cultura andina a partir de la reconstrucción y apropiación de los principales signos visuales presentes piezas que aún se albergan en museos, yacimientos y otros vestigios, los mismos están cargados de simbolismo que hace referencia a la forma de vida de los antepasados; sus valores, costumbres y creencias. En la actualidad estos signos - símbolos son usados en la mayoría de los casos de forma subjetiva sin considerar el contexto sociocultural en el que se crearon. Estos signos al repetirse una y otra vez sin lógica y sin ningún objetivo más que el de acompañar una composición, ha hecho que el individuo los asocie con el pasado, pero está muy lejos de entenderlos y valorarlos en todas sus escalas.

Si bien entender el simbolismo y orígenes de las manifestaciones de estas culturas, no se puede hacer a un lado la influencia de las nuevas culturas que fueron impuestas y que con el paso del tiempo se fueron fusionando con las culturas de los pueblos originarios de américa precolombina y que hoy ya son parte de la identidad socio cultural actual.

Sumado a esto la falta de producción de información visual propia acompañado de las nuevas tecnologías se ha visto reemplazada por la llegada de imágenes extranjeras que si bien gozan de estética no corresponden a la realidad sociocultural del medio donde se difunden.

Por ello, en este artículo se quiere hacer un aporte a la reconstrucción y apropiación de esa identidad perdida, creando nuevas representaciones con los principales signos visuales de las culturas precolombinas, estableciendo una dinámica entre pasado, presente y 
modernidad.

\section{Metodología}

Gracias al interés de varios investigadores por entender y transmitir conocimientos especializados en este tema, actualmente contamos con varios estudios que sirven de referencia para poder llevar a cabo esta propuesta gráfica. De estas investigaciones destacan; el trabajo de Carlos Milla Villena en el Libro "Génesis de la cultura Andina" en el cual plantea y demuestra hipótesis acerca del uso de la Geometría Sagrada, como principio cosmológico, en las obras creadas por el hombre andino. La cual servirá de cómo principio fundamental en la elaboración de las ilustraciones. Zadir Milla Euribe, quien en su libro "Semiótica del Diseño Andino Precolombino", hace un análisis gráfico en cual define los aspectos simbólicos y figurativos del diseño andino. El cual nos provee de recursos gráficos y compositivos para la elaboración de las nuevas ilustraciones. Por otro lado, el trabajo de César Soderguer, quien ha hecho estudio sobre la estética precolombina, en el que cual determina los principios estéticos del arte precolombino. Además, existen varias publicaciones que recogen la iconografía de varias culturas precolombinas, y que servirán como referencia.

\section{Contenido}

Para empezar este estudio es importante ubicarnos en un marco geográfico de las culturas que serán usadas como referencia en este estudio, acotando que el área andina se desarrolló dentro del territorio de los Andes Centrales, que comprende desde el norte de Colombia hasta el Sur de Chile incluyendo los territorios del Perú, Bolivia, norte de Chile, noroeste de Argentina y sur del Ecuador. En este territorio existió un amplio repertorio de culturas y sub-culturas diferenciables, pero que, en sus caracteres generales, todas forman parte de la gran unidad tradicional de la cultura andina, propia, originaria y peculiar.

\section{Filosofía Andina}

Entendemos por "filosofía", una concepción de la vida que tiene una persona o un pueblo, una forma de existencia, una manera de explicarse el mundo. los pueblos andinos desarrollaron su propia forma de vida, religiosa, científica, social, entre otros, que les sirvió para formarse una idea del mundo o una filosofía de la vida.

Según Esterman (2006) la 'filosofía andina' es el conjunto de concepciones, modelos, ideas y categorías vividos y experimentados por el hombre andino, es decir: la experiencia concreta y colectiva del ser humano andino en su universo físico y simbólico.

Entre los pueblos andinos, se observan siempre signos que se repiten, los mismos que son claves para entender su forma de pensar. En el variado repertorio cultural de estos pueblos, encontramos una gran similitud entre sus mitos, ritos y tradiciones sagradas, así como el gran parecido entre los principales símbolos, lo cual muestra que se manejaban bajo una misma estructura.

"Para la filosofía andina, la 'realidad' está presente (o se presenta) en forma simbólica, y no tanto representativa o conceptual. El primer afán del runa/jaqi andino no es la adquisición 
de un 'conocimiento' teórico y abstractivo del mundo que le rodea, sino la 'inserción mítica' y la representación cultica y ceremonial simbólica de la misma". (Esterman 2006; p 104)

A continuación, se hace un resumen breve de los principios que según Esterman (2009) explican cómo funciona el pensamiento andino:

- Principio de relacionalidad u holístico: este principio afirma que todo está de una u otra manera relacionado con todo. Es el principio que explica la coexistencia de la naturaleza (real) y lo social, estas dos realidades están organizadas desde los más simple a los más complejo. Es una visión armónica que integra las maneras de ser, pensar, sentir y actuar.

Principio de correspondencia: se deriva del principio de relación, explica la correspondencia que existe entre la naturaleza y sus elementos, quiere decir que unos términos siempre van con otros términos, unas realidades implican siempre otras realidades.

Principio de complementariedad: es un principio fundamental que muestra cómo los elementos se juntan para formar un todo, en estrecha relación con su complemento, ninguna acción existe de manera individual, uno de ellos solo es una parte del mundo y que no podría existir sin el otro.

Principio de reciprocidad: Este principio es la expresión moral de los demás principios, que gobierna las relaciones del hombre con la naturaleza y con los demás hombres. El hombre andino no es más que un elemento de la naturaleza, al respecto Esterman sostiene que "a cada acto corresponde como contribución complementaria un acto recíproco", es decir que las acciones del hombre andino se basan en la reciprocidad lo que implica ser igualitario y comunitario con los demás hombres andinos.

De acuerdo a cada principio se dedujeron los atributos, que se transformaran en elementos visuales empleados en la construcción de las nuevas ilustraciones.

- Principio de racionalidad: unidad y armonía

- Principio de correspondencia: continuidad

- Principio de complementariedad: orden, igualdad

- Principio de reciprocidad: sucesión, continuación

\section{El Lenguaje}

Se define el lenguaje como el vehículo de comunicación, todo lenguaje está conformado por un conjunto de signos y de símbolos, que a través de la sintaxis crea un discurso organizado.

Milla Euribe, (1990) afirma que, en el Arte Andino, todo el mensaje visual tiene tres niveles de lenguaje; El Lenguaje Visual, El Lenguaje Plástico y el Lenguaje Simbólico, y que estos juntos forman un discurso único e indisoluble. Por ello, si pretendemos crear nuevos signos que se aproximen a este estilo es fundamental conjugar estos tres lenguajes, para ello hemos dividido el estudio en tres partes: 
El Simbolismo que servirá para ponernos en el contexto cultural en el que se desarrollaron las imágenes y así entender las formas de representación, interpretación y expresión visual. La Composición, en esta parte se conocerá y entenderá los signos esquemáticos, que forman parte de este universo gráfico, para poder usarlos como recursos en la creación de los nuevos signos. Finalmente, la Estética en esta parte se determinará la concepción de la forma, la cual aplicaremos a los nuevos signos de manera que estos se aproximen a la estética precolombina.

\section{Simbolismo}

Según Milla Euribe, (1990) el arte precolombino está comprendida básicamente por tres tipos de imágenes, las que se reconocen del mundo real, las imaginarias, y las que proceden del razonamiento calculador, esta concepción se la puede tratar en tres niveles de comprensión: cosmovisión, cosmogonía y cosmología.

Cosmovisión, es la imagen general que tenía el hombre andino acerca del mundo, es decir como percibía e interpretaba la naturaleza y todo lo existente. La cosmovisión define los elementos comunes de las diversas áreas de la vida, así como: la política, la economía, la ciencia, la religión, la moral o la filosofía.

Cosmogonía, pretende establecer una realidad, ayudando a construir activamente la percepción del universo (espacio) y del origen de dioses, la humanidad y elementos naturales.

"La cosmogonía andina explica los orígenes y poderes de las entidades naturales, interpretándolas concepciones mágico-religiosas en la cuales lo mítico se explica por los valores de correspondencia y las relaciones de analogía entre lo real y lo sobrenatural, lo conocido y lo desconocido." (Milla Euribe 1990; 8).

La importancia de conocer y entender como la cosmogonía andina es que nos permitirá ubicar los signos dentro un contexto 'real', el del mundo andino, que a su vez tenga una equivalencia dentro de este, y este representarlo efectivamente.

Cosmología, comprende el conjunto de conceptos que expresan el orden básico del universo: las entidades que lo componen, la geometría de sus espacio y tiempo, las fuerzas y reglas promotoras de los acontecimientos naturales y sociales y además la clasificación de estos en un patrón coherente.

Estos tres constituyen los planos de significación de los cuales se genera el naturalismo, el simbolismo y la abstracción geométrica como una respuesta estética de la forma al contenido.

\section{Geometría Sagrada: Proporción Andina.}


Los autores dedicados a estudiar el conocimiento indígena americano coinciden en señalar que la geometría abstracta, fue la característica central y definitoria del conocimiento andino.

"En el pensamiento andino el ordenamiento de números a determinados significados o contextos significativos se encuentra íntimamente unido al devenir cíclico del acontecer del universo. Cada cosa, cada sitio tiene su sitial numérico y su valor determinado, todo este ordenamiento e interrelación de acontecimientos conocemos bajo el concepto de "orden cósmico". Este orden manifiesta en primera instancia como cualidad religiosa que es expresada en la matemática ritual. En esferas subsiguientes se ordenan las correspondencias elementales y cromáticas; siguiendo este orden se suman a ella las correspondencias místicas, zoomorfas y vegetales, como también los puntos cardinales, los planetas y todo lo existente." (Miranda 1991)

Milla Villena (1983), sugiere que el hombre andino derivó sus matemáticas jugando geométricamente con el cuadrado y el círculo, para fundamentar su hipótesis el autor nos presenta abundante evidencia arqueológica, arqueo-astronómica y documental en su libro, Génesis de la cultura Andina. Y que en ella se puede apreciar la persistente presencia del símbolo de la Cruz Cuadrada en muchas de sus representaciones. Este símbolo tuvo un profundo significado matemático - religioso y fue venerado durante los seculares rituales como símbolo ordenador del mundo andino. Ante esto se piensa que en efecto debió haber habido un sistema matemático que regía el sistema social andino.

"Como se ha comprobado esta singular 'geometría' lo inspira todo, está íntimamente ligada a su concepto de la unidad y al Sistema Operativo que desarrolló como parte de su Técnica Arquitectónica. Por lo tanto, no se puede analizar ninguna de sus estructuras materiales sin conocer esta estructura mental en base a la cual se desarrolló su Cultura" (Milla Villena,1983)

De esto, se asume que para crear signos que se aproximen a este pensamiento es imprescindible entender cómo funciona este sistema. Para ello, se tomó como base la evidencia de estos juicios, repasando los principios ya establecidos y haciendo análisis propios de la gráfica ya estudiada, para comprobar los planteamientos y aplicarlos.

\section{Composición}

La composición se define como una distribución o disposición de todos los elementos que incluiremos en un diseño, para obtener una forma perfecta y equilibrada.

En el Arte Andino las composiciones obedecen a los principios de la Geometría Sagrada que es la expresión de la cosmología. Estos principios aparecen bajo la forma de signos o estructuras compositivas

\section{La Proporción}

La proporcionalidad del espacio, se determina por el proceso formativo de una figura 
inscrita en un cuadrado, un rectángulo o un círculo como principio general formativo. La particularidad de la Proporción Andina es que, esta tiene su inicio en el cuadrado que actúa como modular y principio formativo, de cual se derivan las construcciones del rectángulo y el círculo.

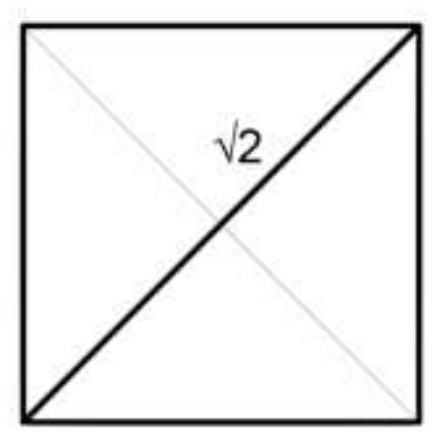

Milla Z. (1990) El cuadrado. Ilustración.

Recuperado: Semiótica del Diseño Andino

\section{El Trazado Armónico.}

El hombre andino desarrolló procedimientos de construcción proporcional, para conseguir un orden armónico en sus composiciones, tales procedimientos regulan el espacio y las proporciones de las formas relacionadas con dicho espacio, a esta técnica se le denomina trazado armónico.
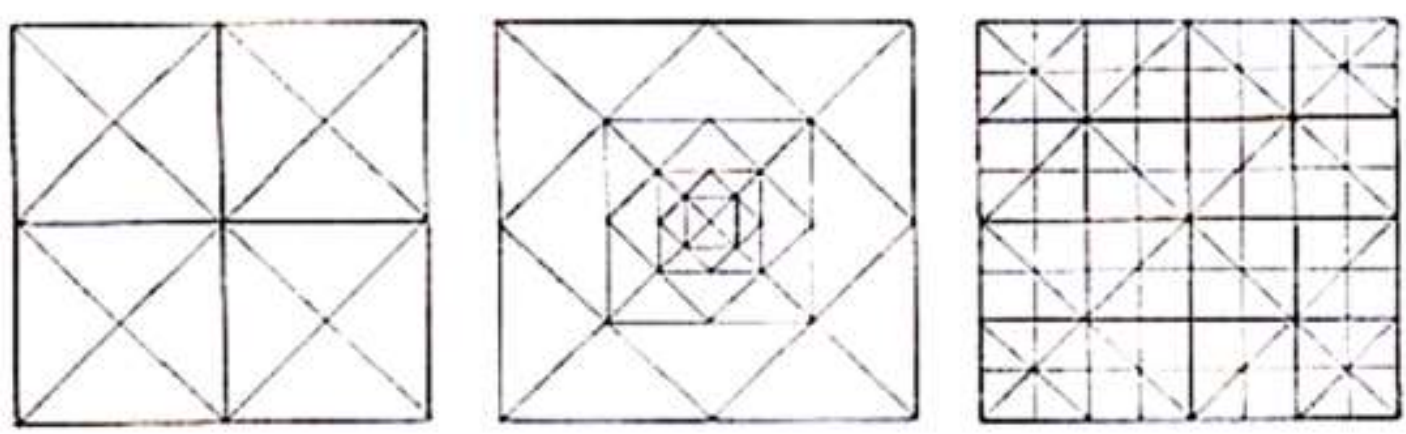

Milla Z. (1990). Bipartición. Ilustración.

Recuperado: Semiótica del Diseño Andino

La técnica del trazado armónico para la creación de formas, será fundamental en el proceso de creación de los nuevos signos, ya que este además de permitirnos ordenar el espacio y lograr proporciones armónicas, se usó, como retícula en la construcción de todas las figuras, esto generó una serie de rasgos análogos consiguiendo la unidad, lo que nos ayudó a consolidar el estilo. 
Para la formación de las figuras, se usaron las siguientes estructuras de composición:

- El cuadrado, como elemento único de composición.

- La dualidad, cuatripartición o tripartición

- La diagonal, el triángulo, rombo y la espiral

- La Cruz cuadrada

En el proceso, en primer lugar, trazamos la retícula considerando la forma de cada figura, posteriormente se trasladaron los bocetos, haciendo coincidir los trazos con los gnómones, de manera que la lógica se fusionó con las representaciones de las formas

\section{Estética}

Por otro lado, en América Precolombina existieron diversidad de culturas lo que a su vez generó diversidad de estilos cada uno de ellos con características propias. Por lo cual hacer un análisis de cada uno requería un estudio más profundo, es por eso que aquí se propone hacer un análisis personal, en el cual se determinarán los rasgos (formas de representación) comunes y los rasgos independientes (únicos de cada cultura) que, a criterio del autor, aporten a la creación de los nuevos signos.

\section{La Representación}

Arnhem (1980) nos ofrece en un artículo titulado "La abstracción perceptual en el arte" en el que plantea:

"La representación consiste en $<<v e r ~<<$ dentro de la configuración estimular un esquema que refleje su estructura (...) y luego inventar un equivalente pictórico para ese esquema" $(p, 42)$

De esto sabemos que la representación es el resultado de la interacción de dos esquemas, uno perceptivo y otro pictórico; el primero es un equivalente de la realidad, el segundo es una réplica plástica de precepto. Dicho de otra forma, la representación es un equivalente plástico del precepto o lo que es lo mismo de la estructura del estímulo.

Por lo que la interpretación gráfica de las figuras se resolvió desde e

\section{Resultados}

\section{Abstracción de los referentes reales}

Mediante la técnica de la abstracción geométrica, se hizo una selección y síntesis de los rasgos dejando a un lado los detalles inútiles, y rescatando los rasgos predominantes con los cuales se aseguró el reconocimiento del referente. Finalmente, estas abstracciones se fusionaron con los rasgos recogidos, logrando la aproximación estética deseada.

\section{Extracción de rasgos}


El objetivo de este proceso fue reunir varios rasgos gráfico-plásticos, como recursos para la creación de las nuevas ilustraciones. Para ello se definieron los principales rasgos físicos de cada unidad morfológica según el referente real, y se describió detalladamente la forma de representación de cada uno, al mismo tiempo se hizo una comparación de los rasgos, en la que se observaron las similitudes y diferencias entre las diferentes culturas.
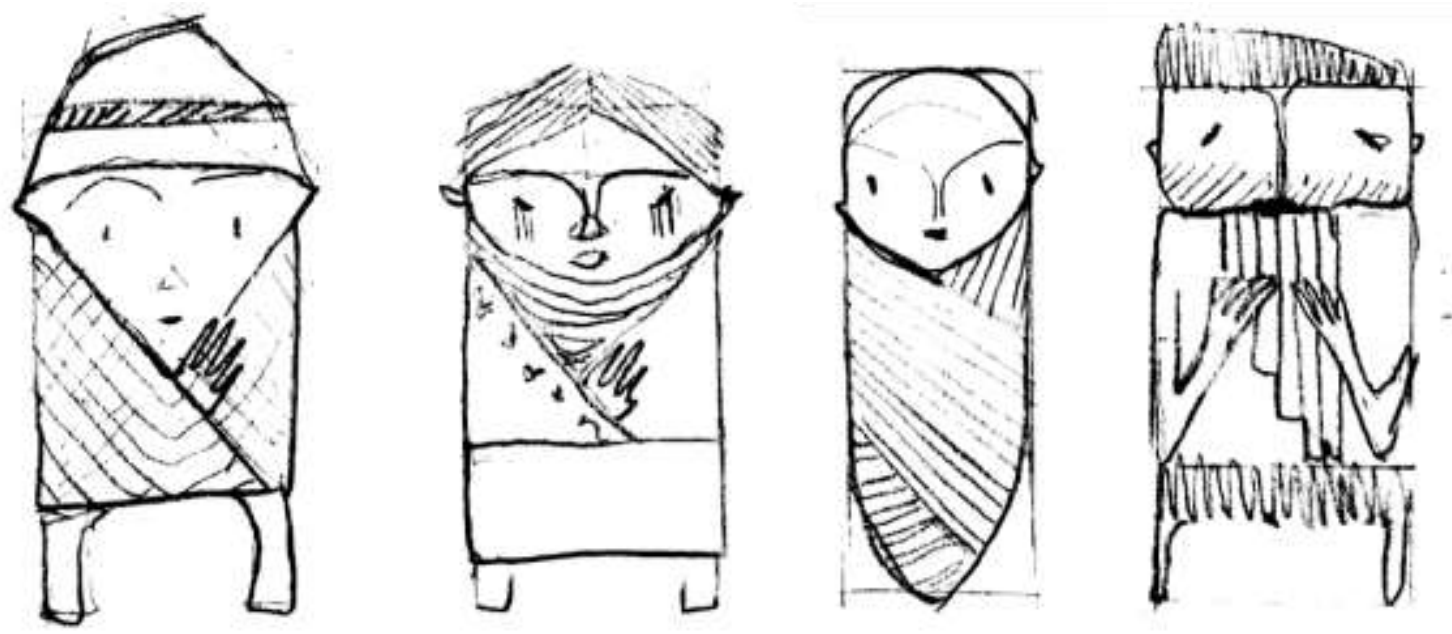

Bocetos del autor: Rosa Ramos

\section{Selección Temática}

Para la selección de la temática, partimos de la clasificación que se hizo con respecto a los principales temas de representación en el arte precolombino, a los cuales denominamos unidades morfológicas, entre estas tenemos:

- Unidades Fitomorfas (Flores, Plantas y Hojas)

- Unidades Zoomorfas (Llama, Colibrí, Paloma, Loro, Pájaro)

- Unidades Antropomorfas (Hombre Indígena, Mujer Indígena, Shaman y Rostros)

\section{Unificación de Estilo}

Como se ha descrito se usó los mismos procesos para crear cada figura, de lo que resultó, un conjunto de figuras similares. Conforme se adaptaron las figuras a las retículas compositivas estas adquirieron las cualidades geométricas, propias de la gráfica andina.

Para la definición de la forma, se usó la figura un solo plano bidimensional, en el cual se ubicaron todos los elementos que definieron la figura. Como principales rasgos figurativos, se usaron puntos, líneas y planos, como elementos únicos o repetidos en serie, para representar o sugerir una forma. 
Civallero E. (2008.) Culturas andinas y ubicación. Mapa. Recuperado: http://www.culturaspopulares.org/textos6/articulos/civallero.html 

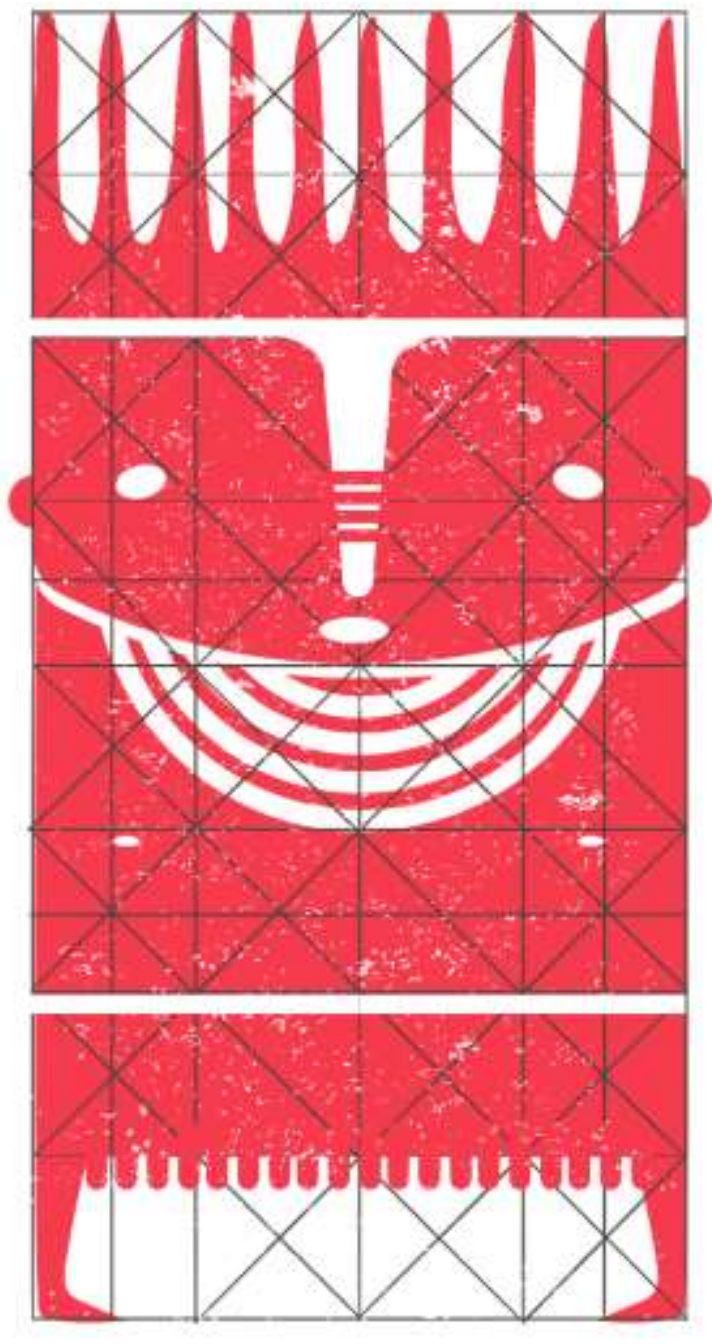

\section{Cacique - Shaman}

1. Simbolismo:

El chomón, quién ejecuta el ritual, es el mediodor entre lo cerrend y el mundo espirtual A través de estados modiffcados de consciencia, provocodos por el consumo de olucinógenos, por bolleso por sonidos monótonos, entri en trance y logra cominicarse con los fuerzas que lo ayudorán a sanar, predecit, acansejar, entre ctros.

\section{Composición}

Reticula Compositiva: 2 Cuadrados

\section{Estética}

\begin{tabular}{l} 
Estilo: Abstracto Geométrico \\
\hline -Plano Bidimensional \\
-Adaptación de Cabeza \\
-Adaptoción de Brozos, Piernas, Manos y Pies \\
\hline -Adaptoción de Ojos, naríz, boca y orejas. \\
-Adaptoción de vetsuario (Falda] \\
\hline -Adaptoción Accesorios [Collar) \\
-Adaptoción Cabello. \\
- Vértices redondeodas \\
\hline -Texturas. Agrietada
\end{tabular}




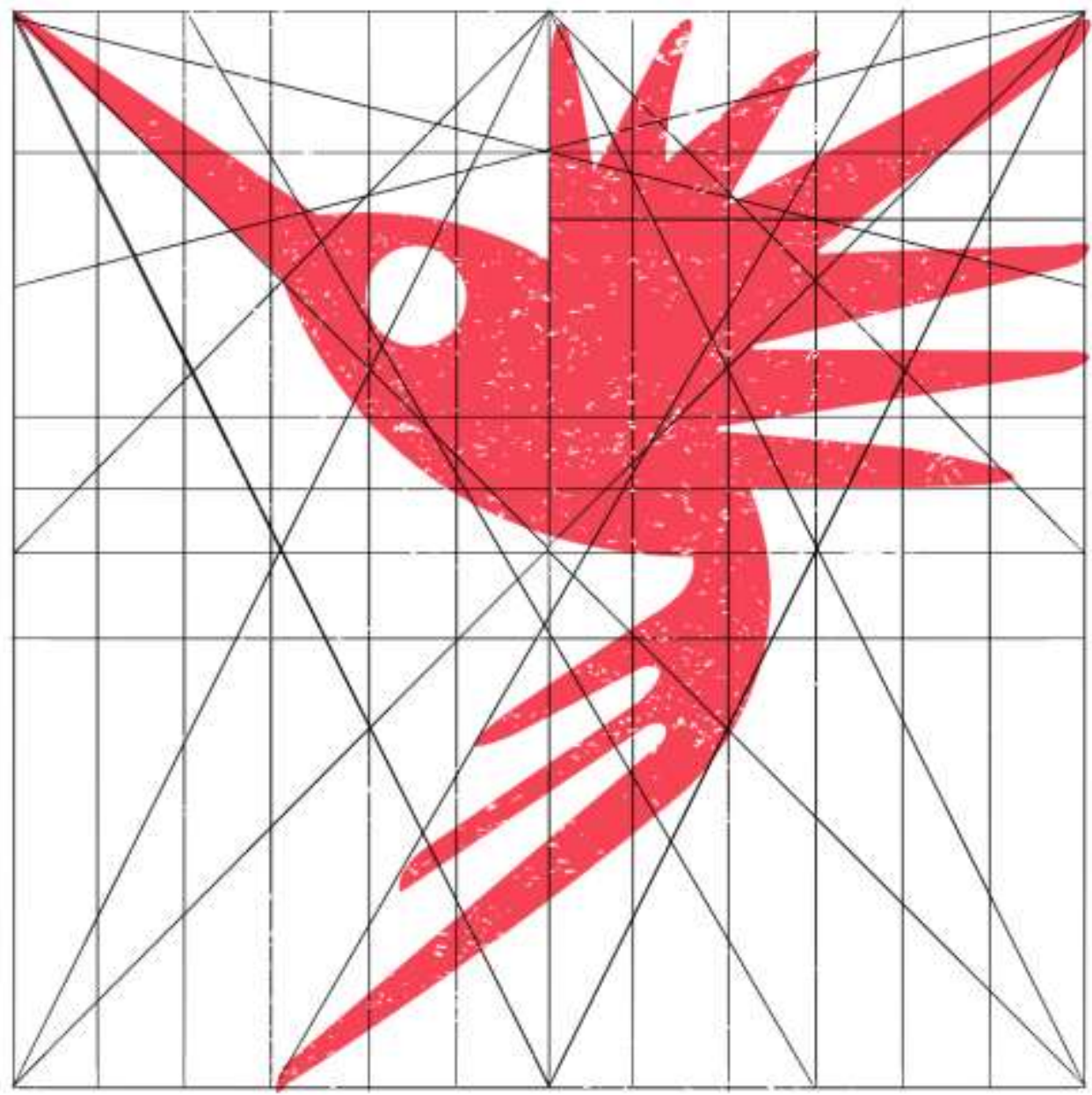

\section{Aves - Colibrí}

\section{Simbolismo:}

El significado de la representación pictórica y escultórica del Colibri en las culturas precolombinas se relaciona con los usos que tienen actualmente en los Andes, sobretodo a la simbolización del poder politico, el poder religioso del Chamán y la fertilidad de la tierra.

\section{Composición:}

Retícula Compositiva: Cuadrodo

\section{Estética:}

\begin{tabular}{l}
\hline Estilo: Abstracto Geométrico \\
\hline - Estilización de Alas \\
- Estilización de Ojos \\
- Vértices redondeadas \\
- Texturas: Agrietada
\end{tabular}




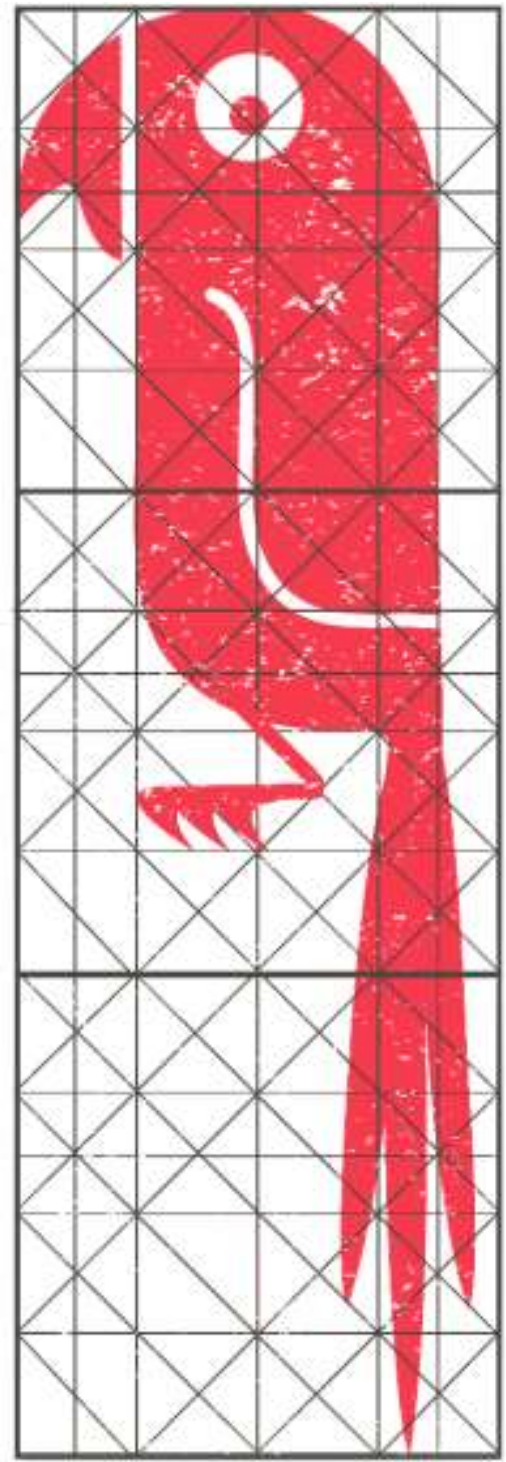

\section{Aves- Loro}

\section{Simbolismo:}

Ei significado de las aves se le suele asociar con la belleza, con las actividades guerreras; e ideas de vuelo y pensarrientos imoginativos o subimes. Se considera como simbolo intermediario o mensciero entre tierra y ciela, función expresomente atr buido o las oves y pójoros en generol y por extensión a todas las plumas, como las que dan direccionolidad al welo de las fiechos.

\section{Composición}

Retícula Compositiva: 3 Cuadrados

\section{Estética}

Estilo:Abstracto Geomécrico

- Plano Bidimensional

- Adaptación de Alas

- Adaptación de Patas

- Adaptación de 0jos

- Vértices redondeadas

- Texturas: Agrietnda 


\section{Conclusiones:}

- De la investigación se concluye que el pensamiento Andino está relacionado con el concepto de la unidad, que se ve reflejado en sistema geométrico, desarrollado en varias estructuras materiales, por lo tanto, no se puede producir ninguna de sus estructuras sin conocer su filosofía.

- Igualmente, concluimos que el mensaje visual andino, tiene tres niveles de lenguaje: el visual, el plástico y el simbólico, juntos forman un mensaje único e indisoluble. Por lo tanto, se puede afirmar que no se puede crear nada sin significado.

- Existen signos (estructuras compositivas ocultas y elementos figurativos) recurrentes en la gráfica precolombina, que constituyen un sistema gráfico el cual ha de tenerse en cuenta para la producción de nuevas imágenes que quieran aproximarse a dicha gráfica.

- Finalmente podemos concluir que las formas analizadas en las piezas de las distintas culturas precolombinas tienen características estilísticas similares, las cuales han posibilitado la creación de las ilustraciones con un estilo aproximado a la gráfica andina, respondiendo a la hipótesis planteada en la investigación.

\section{Referencias bibliográficas.}

Centro de escritura Javeriano (Ed.). (2013). Normas APA. Cali, Colombia: Pontificia Universidad Javeriana. Recuperado de: http://portales.puj.edu.co/ftpcentroescritura/Recursos/Normasapa.pdf

Dondis, A. (1985). La sintaxis de la imagen Introducción al alfabeto visual. Barcelona: Editorial Gustavo Gili, SA.

Esterman, J. (2009). Filosofía Andina. La Paz: ISEAT.

Grass, A. (1976). Animales Mitológicos. Bucaramanga, Colombia: Ed. Triblos

Milla, C. (1990). Génesis de la Cultura Andina. Perú: Auspicia Fondo Editorial C.A.P. Colección Bienal.

Milla, C. (2003). Ayni. Lima: Ediciones Amaru Wayra.

Miranda, J. (1991). Matemáticas Andinas y Cosmología. La Paz: Garza Azul.

Milla, Z. (2008). Introducción a la Semiótica del Diseño Andino Precolombino. Lima: Asociación de Investigación y Comunicación Cultural Amaru Wayra.

Rojas, R. (1953). Silabario de la decoración americana. Bueno Aires: Editorial Losada.

Romero, H. (2006) América Mágica: simbiosis de cantos y ecuaciones. Bolivia: Plural Editores.

Soderguer, C. (1999). Diseño precolombino. Catálogo de icono- grafía Mesoamérica, Centroamérica-Suramérica. Buenos Aires Argentina: Ediciones Corregidor. Wong W. (1995). Fundamentos del diseño. Barcelona: Ed. Gustavo Gili. 


\section{PARA CITAR EL ARTÍCULO INDEXADO.}

Ramos Jiménez, R., Rivera Abarca, A., Aguilar Cajas, H., \& Vergara Zurita, H. (2019). Representación gráfica de la cultura andina. Ciencia Digital, 3(2.6), 73-86. https://doi.org/10.33262/cienciadigital.v3i2.6.519

\section{LCiencia}

El artículo que se publica es de exclusiva responsabilidad de los autores y no necesariamente reflejan el pensamiento de la Revista Ciencia Digital.

El artículo queda en propiedad de la revista y, por tanto, su publicación parcial y/o total en otro medio tiene que ser autorizado por el director de la Revista Ciencia Digital.
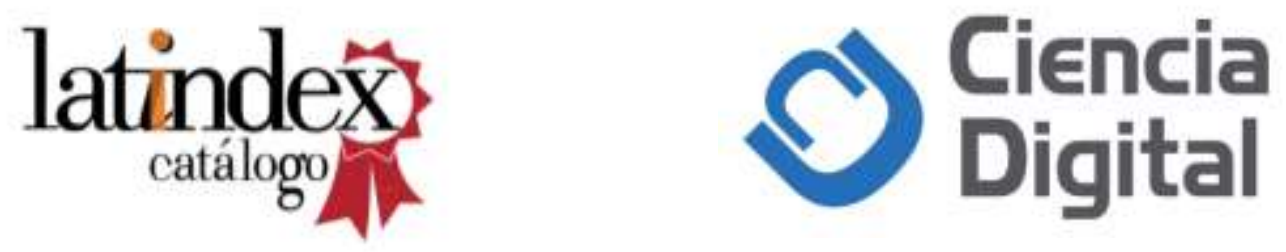